\title{
Severe hepatic complications of antituberculous therapy
}

\author{
Mark O Turner MD CM FRCPC, R Kevin Elwood MD MRCP(UK) FRCPC
}

\begin{abstract}
MO Turner, RK Elwood. Severe hepatic complications of antituberculous therapy. Can J Infect Dis 1999;10(2):167-169.

Hepatotoxicity from antituberculous therapy is well described, but fortunately severe complications are rare. The optimal methods of monitoring for significant hepatotoxicity while on treatment are uncertain. Some authorities recommend measuring liver enzymes only if symptoms develop, whereas others recommend regular liver enzyme monitoring throughout the course of therapy. In British Columbia, from 1990 to 1997, 2624 active and approximately 8000 chemoprophylaxis cases have been treated, but only two severe complications directly related to antituberculous therapy have occurred. A 33-year-old male developed fulminant hepatic failure seven months after starting isoniazid chemoprophylaxis and required a liver transplant. The other patient died from hepatic failure that developed in the first month of triple-drug therapy for proven active pulmonary tuberculosis. The early and late onset of hepatic failure associated with antituberculous therapy in these cases underline the difficulties in identifying a monitoring protocol that will totally negate the risk of severe complications.
\end{abstract}

Key Words: Chemoprophylaxis, Hepatotoxicity, Isoniazid, Liver transplantation

\section{Complications hépatiques graves du traitement antituberculeux}

RÉSUMÉ : L'hépatotoxicité causée par le traitement antituberculeux est bien décrit, mais heureusement, les complications graves sont rares. Certaines autorités recommandent un dosage des enzymes hépatiques seulement si les symptômes s'installent, alors que d'autres recommandent la vérification régulière des enzymes hépatiques tout au long de l'antibiothérapie. En Colombie-Britannique, de 1990 à 1997, 2624 cas actifs et environ 8000 cas de chimioprophylaxie ont été suivis, mais seulement deux complications graves ont été reliées au traitement antituberculeux. Un homme de 33 ans a développé une insuffisance hépatique fulminante sept mois après le début d'une chimioprophylaxie à l'isoniazide et a nécessité une transplantation hépatique, l'autre patient est décédé des suites d'une insuffisance hépatique qui s'est installée au cours du premier mois d'une trithérapie pour tuberculose pulmonaire active. Le déclenchement précoce et tardif de l'insuffisance hépatique associée au traitement antituberculeux dans ces cas rappelle à quel point il est difficile de mettre sur pied un protocole de surveillance apte à éliminer entièrement tout risque de complications graves.

I

soniazid (INH) is a vital drug used both for tuberculosis

(TB) treatment and preventative therapy. The drug has been in use for over 40 years and is generally considered safe. Hepatotoxicity, however, occurs in up to $10 \%$ of patients taking INH (1) and in $11 \%$ of patients taking triple-drug therapy for active TB (2). Fulminant hepatic failure is an infrequent but devastating complication of antituberculous medication. We have treated 2624 cases of active TB from 1990 to 1997 in the province of British Columbia and prescribed chemoprophylaxis treatment to 8014 patients. We describe two cases of fulminant hepatic failure associated with antituberculous therapy.

Division of Tuberculosis Control, British Columbia Centre for Disease Control, Division of Respiratory Medicine, University of British Columbia, Vancouver, British Columbia

Correspondence and reprints: Dr MO Turner, Division of Tuberculosis Control, British Columbia Centre for Disease Control, 655 West 12th Avenue, Vancouver, British Columbia V5Z 4R4. Telephone 604-660-6114, fax 604-660-1950, e-mail mark.turner@bccdc.hnet.bc.ca Received for publication January 12, 1998. Accepted January 26, 1999 


\section{CASE PRESENTATIONS}

Case 1: A 33-year-old Aboriginal man was screened because of possible contact with an active case of TB. His tuberculin skin test (5 tuberculin units PPD) was positive, $15 \mathrm{~mm}$, with no history of Bacille Calmette-Guérin vaccine. Chest radiograph was normal. INH chemoprophylaxis, $300 \mathrm{mg}$ daily, was recommended and arranged through his family physician. Baseline liver enzymes were normal in June 1995. The patient delayed starting INH chemoprophylaxis until October 1995. He was scheduled to see a TB control physician in November 1995 at an outreach clinic but did not attend. One week later, he picked up his second month of medications and was given a twomonth supply because of travel and work commitments. He subsequently picked up medications from nurses at the public health unit in February and April 1996. The nursing notes from the last visit, April 16, 1996, reported the patient to be well with no evidence of jaundice. He was also given the first of a series of hepatitis $B$ vaccinations.

The patient presented to the emergency department 12 days later with scleral icterus and dark urine, first noticed that day. He admitted to drinking a large amount of alcohol one week earlier. He was feeling well enough to have gone jogging the day before presentation. The patient was advised to stop the INH immediately and to be further assessed by his family physician. Blood work from the emergency department showed elevation of liver enzymes: aspartate aminotransferase (AST) $1874 \mathrm{U} / \mathrm{L}$ (normal range 10 to 40), alanine aminotransferase (ALT) $1564 \mathrm{U} / \mathrm{L}$ (10 to 60), gamma-glutamyl transpeptidase (GGT) $244 \mathrm{U} / \mathrm{L}$ (10 to 65), total bilirubin $255 \mathrm{~mol} / \mathrm{L}$ (0 to 20) and alkaline phosphatase $251 \mathrm{U} / \mathrm{L}$ (40 to 120). Hepatitis and human immunodeficiency virus serology were negative. He continued to deteriorate, and AST peaked eight days after stopping INH at $4394 \mathrm{U} / \mathrm{L}$, bilirubin $455 \mathrm{~mol} / \mathrm{L}$ and partial thromboplastin time $43 \mathrm{~s}$. He was admitted to hospital May 13, 1996 with symptoms of abdominal pain and confusion in advanced hepatic encephalopathy. The patient was comatose on the following day and required endotracheal intubation. AST was $1087 \mathrm{U} / \mathrm{L}$, bilirubin $522 \mathrm{~mol} / \mathrm{L}$, partial thromboplastin time $104 \mathrm{~s}$. He was transferred to the Vancouver General Hospital, a regional transplantation centre on May 15, and underwent an orthotopic liver transplant on May 16. He was discharged from hospital on June 10, 1996 in good condition.

Pathology of the hepatectomy specimen showed subacute hepatocellular necrosis with no identifiable cause.

Case 2: A 76-year-old man emigrated from Hong Kong to Canada in January 1992. The immigration chest radiograph showed calcified granulomata at the right apex and pleural thickening. Initial sputums for immigration surveillance were smear and culture negative. At a follow-up, one year later, there was a change in the chest radiograph suggestive of active disease. Sputums were smear negative but culture positive for Mycobacterium tuberculosis, fully sensitive to all first-line medications. The patient denied any symptoms. He was diabetic and had no history of hepatitis.

Baseline liver enzymes showed AST to be $30 \mathrm{U} / \mathrm{L}$. On October 10, 1993, the patient was started on INH $300 \mathrm{mg}$, rifampin
$600 \mathrm{mg}$ and pyrazinamide $1.5 \mathrm{~g}$, daily self-administered. The patient weighed $70 \mathrm{~kg}$. He returned to the clinic October 22 for a routine follow-up. Apparently, he was not taking the INH and was advised to start it at that time. The patient attended his personal physician November 5, 1993, complaining of fatigue and anorexia for several days. He was jaundiced, and all antituberculous medications were discontinued. AST was elevated to $4084 \mathrm{U} / \mathrm{L}$. He was admitted to hospital in a coma three days later. Liver enzymes in hospital were AST $3233 \mathrm{U} / \mathrm{L}$, ALT 4298 U/L, GGT 372U/L, alkaline phosphatase $122 \mathrm{U} / \mathrm{L}$ and bilirubin $189 \mathrm{~mol} / \mathrm{L}$. The patient was not considered a candidate for liver transplantation and died six days later. Serology for hepatitis A and B were negative. No autopsy was performed.

\section{DISCUSSION}

These two cases highlight the difficulties of monitoring patients for hepatotoxicity when taking antituberculous therapy. We believe the fulminant hepatic failure in both cases is attributable to INH, possibly due to potentiation of toxicity from rifampin in the second case $(3,4)$. The short duration of symptoms before developing irreversible hepatic necrosis raises concerns about the ability of any monitoring protocol that depends on symptoms alone to give sufficient warning $(5,6)$.

The first patient had completed six-and-a-half months of INH chemoprophylaxis. In the province of British Columbia, the policy is to give INH chemoprophylaxis for 12 months. Follow-up blood work was not completed because of miscommunication between the public health unit where he picked up the medications and his family physician. Although the patient had gone through an alcohol treatment program, it was probable that he continued to drink and he admitted to binge drinking before becoming jaundiced. We are not aware of any reports of hepatitis B vaccination potentiating INH hepatotoxicity. In this patient's case, there was no liver enzyme monitoring, and the patient was seen only every two months. Other reports have highlighted fatalities occurring because of continued treatment despite evidence of hepatotoxicity by liver enzyme measurement (7).

The second case was an older man who had minimally active disease. He was taking self-administered treatment but was closely followed. Apparently, he was not taking INH for the initial 10 days treatment and took it for the last 12 days before presenting to his family physician with liver failure. We can only surmise that the INH precipitated the acute fulminant hepatic failure because he was also taking rifampin and pyrazinamide.

The incidence of fulminant hepatic failure in our clinic in a seven-year period is $1.88 / 10,000$. A study of 13,838 patients receiving INH chemoprophylaxis in the United States (8) reported eight deaths (incidence $5.78 / 10,000$ ), a rate almost three times greater than our data for patients receiving active therapy and chemoprophylaxis.

Risk factors for hepatotoxicity include older age, female sex and extensive disease (9). Recommendations for monitoring liver function differ greatly. The British Thoracic Society 
recommends a baseline measurement but no further testing unless symptoms develop except for routine monitoring in alcoholics and in those with liver diseases (10). The American Thoracic Society recommends baseline blood work including liver functions in patients on active treatment and then as indicated by symptoms (11). For patients taking preventive therapy with INH, baseline and monthly transaminase monitoring is recommended for all patients older than 35 years (11). In general, even for the younger age group, we recommend a pretreatment measurement of AST, monthly measurements for the first three months and then every two to three months thereafter or as indicated by symptoms. However, as these two cases illustrate, depending on symptoms alone to prompt liver function measurements clearly risks irreversible liver damage.

These two cases illustrate the potentially catastrophic side effects of hepatotoxic medications and underline the difficulty in appropriately monitoring and caring for these patients. The first case was not monitored according to our policy and may have been preventable. The second case was managed appropriately, and there appears little that could have been done differently, even in retrospect. The cases also illustrate that hepatic necrosis can occur early or late in the course of therapy despite many months of uneventful tolerance.

Do we accept the inevitable, that some patients will die

\section{REFERENCES}

1. Sharer L, Smith JP. Serum transaminase elevations and other hepatic abnormalities in patients receiving isoniazid. Ann Intern Med 1969;71:1113-20.

2. Schaberg T, Rebhan K, Lode H. Risk factors for side-effects of isoniazid, rifampin and pyrazinamide in patients hospitalized for pulmonary tuberculosis. Eur Respir J 1996;9:2026-30.

3. Steele MA, Burk RF, DesPrez RM. Toxic hepatitis with isoniazid and rifampin: a meta-analysis. Chest 1991;99:465-71.

4. Lee WM. Drug induced hepatotoxicity. N Engl J Med 1995;333:1118-27.

5. Ormerod LP, Skinner C, Wales J. Hepatotoxicity of antituberculosis drugs. Thorax 1996;51:111-3.

6. Van den Brande P, Van Steenbergen W, Vervoort G, Demedts M. Aging and hepatotoxicity of isoniazid and rifampin in pulmonary tuberculosis. Am J Respir Crit Care Med 1995;152:1705-8.

7. Mitchell I, Wendon J, Fitt S, Williams R. Anti-tuberculous therapy and acute liver failure. Lancet 1995;345:555-6. from adverse effects of antituberculous medications despite protocols designed to avoid severe and fatal complications? The optimal method to determine the impact of any monitoring protocol or recommendation is a randomized controlled trial. However, this approach is problematic and presents ethical dilemmas. Moreover, serious events such as fulminant hepatic failure are rare (3), and what are the right questions to ask? Current recommendations for liver enzyme monitoring are entirely empirical $(5,12)$, and issues of compliance (patient and health care provider) and cost-effectiveness are not addressed. The therapeutic emphasis by programs on directly observed therapy to encourage better compliance and appropriate dosing also affect the monitoring for side effects. A directly observed treatment program, by virtue of more frequent patient contact, facilitates closer monitoring of symptoms and greater likelihood that blood work is done regularly and reviewed promptly. Our cases offer some lessons in that one case of hepatic necrosis occurred late in the course of preventative therapy, which argues for liver enzyme monitoring throughout the entire period of medication delivery. Fatal hepatic necrosis occurred so rapidly in the second case that it is unlikely that any monitoring protocol would have been effective in preventing this outcome. These issues should be considered in any further debate about severe adverse reactions to antituberculous therapy.

8. Kopanoff DE, Snyder DE, Caras GJ. Isoniazid-related hepatitis. A US Public Health Service Cooperative Surveillance Study. Am Rev Respir Dis 1978;117:991-1001.

9. Dossing M, Wilcke JTR, Askgaard DS, Nybo B. Liver injury during antituberculosis treatment: an 11-year study. Tubercle Lung Dis 1996;77:335-40.

10. Ormerod LP, for Joint Tuberculosis Committee. Chemotherapy and management of tuberculosis in the United Kingdom: recommendations of the Joint Tuberculosis Committee of the British Thoracic Society. Thorax 1990;45:403-8.

11. American Thoracic Society. Treatment of tuberculosis and tuberculosis infection in adults and children. Am J Respir Crit Care Med 1994;149:1359-74.

12. Thompson NP, Caplin ME, Hamilton MI, et al. Antituberculosis medication and the liver: dangers and recommendations in management. Eur Respir J $1995 ; 8: 1384-8$. 


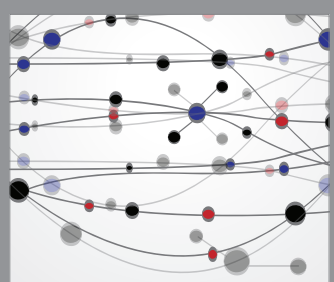

The Scientific World Journal
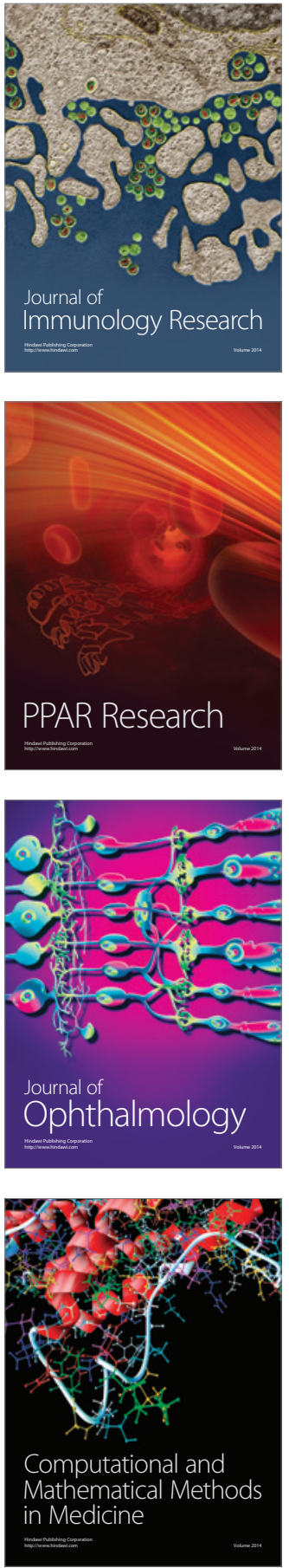

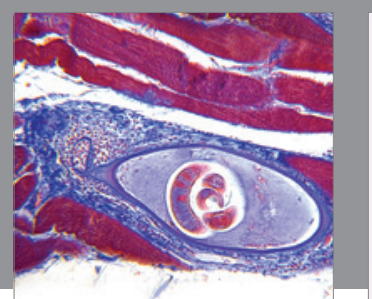

Gastroenterology Research and Practice

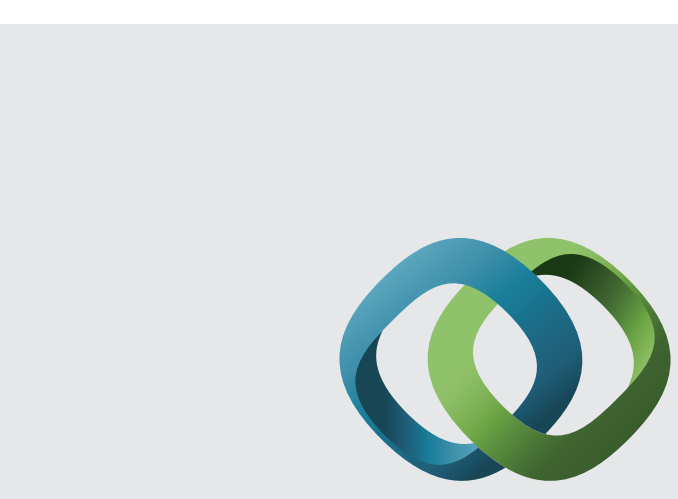

\section{Hindawi}

Submit your manuscripts at

http://www.hindawi.com
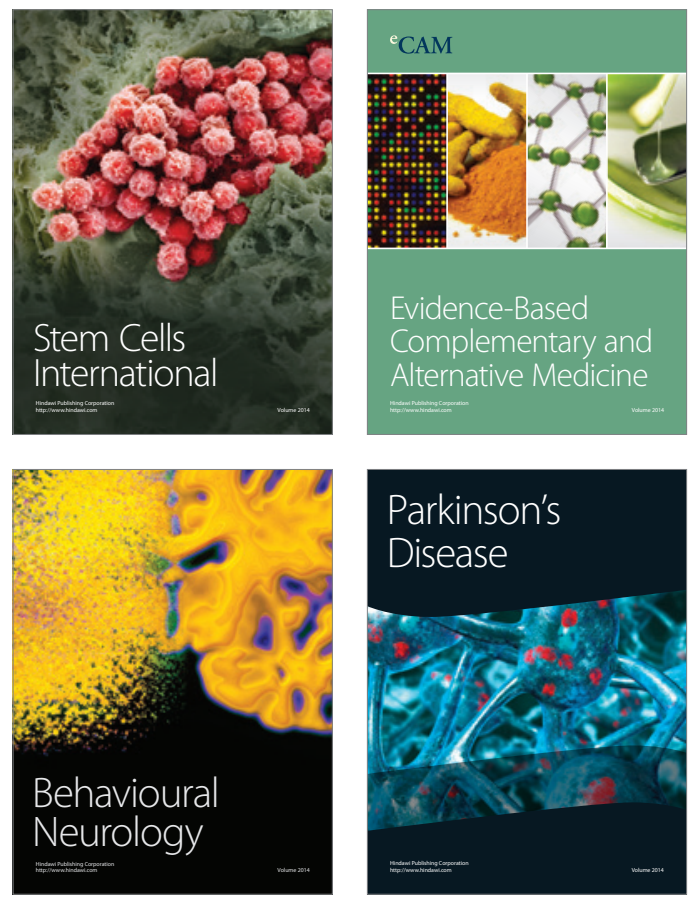
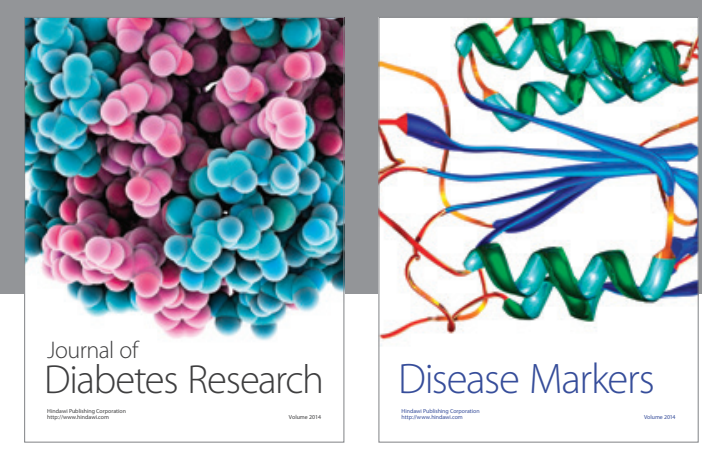

Disease Markers
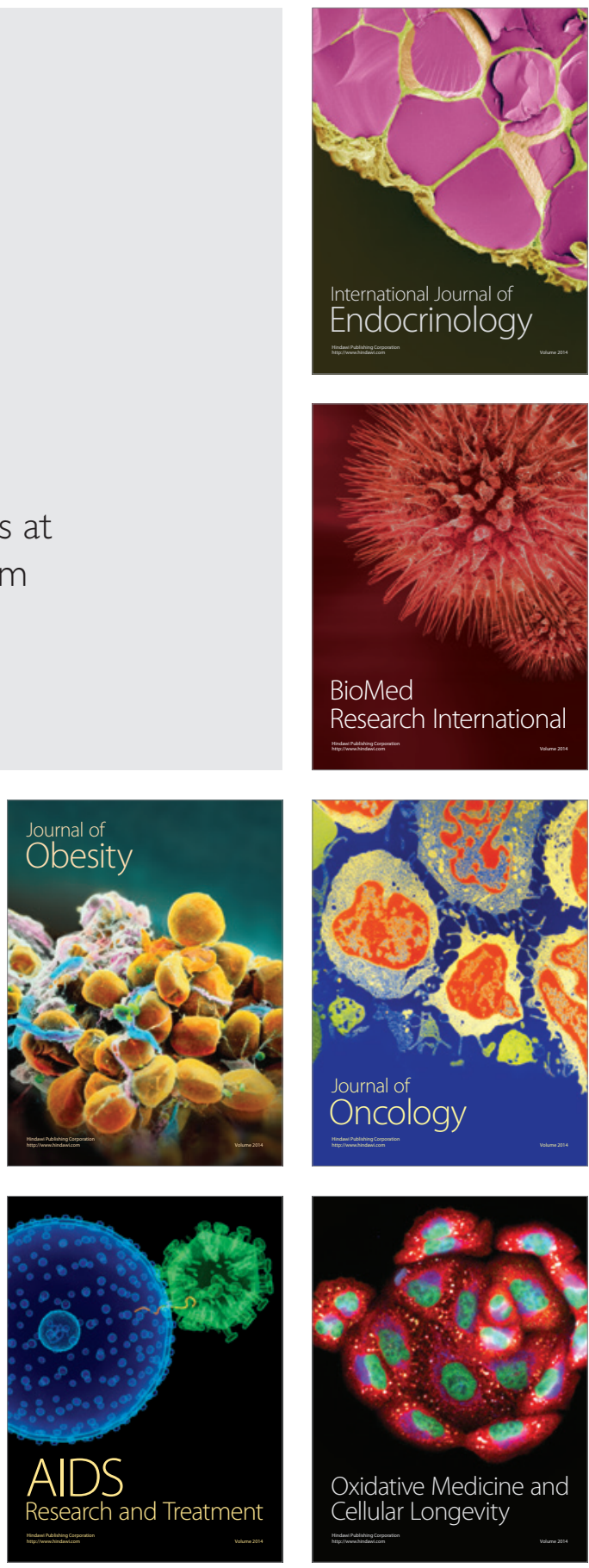